\title{
Surgical Management of Spondylolisthesis by Pedicular Screw Rod System and Postero-Lateral Fusion
}

\author{
M. Chaitanya, Ankur Mittal*, Ramprasad Rallapalli, Ravi Teja, Y. Siva Prasad \\ Department of Orthopaedics, Narayana Medical College and Hospital, Nellore, India \\ Email: ${ }^{*}$ mittal.87@gmail.com
}

Received 18 May 2015; accepted 26 June 2015; published 30 June 2015

Copyright (C) 2015 by authors and Scientific Research Publishing Inc.

This work is licensed under the Creative Commons Attribution International License (CC BY). http://creativecommons.org/licenses/by/4.0/

(c) (i) Open Access

\begin{abstract}
Introduction: Incidence of spondylolisthesis in general population is 5\% - 7\%. No matter what the etiology is, patients usually have significant functional disability. Few studies have investigated the long term effect of posterolateral fusion on functional outcome. Objectives: To study the efficacy of posterolateral fusion in spondylolisthesis especially in terms of functional outcome. Methodology: From July 2010 to June 2012, a total of 86 patients, operated with postero-lateral fusion were followed up and evaluated based on VAS for low back pain, ODI and neurological deficits. Results: Follow up was 83\% of original study population (86). Average follow up was 13 months. The mean difference between pre-operative and post-operative VAS at final follow up was $3.5 \mathrm{cms}$ (SD = 2.94); ODI was $28 \%$ at 4 months and $36 \%$ at 8 months. Claudication pain relieved in all; functional outcome was good in $67 \%$, fair in $27.5 \%$ and failed in $5.5 \%$; $75 \%$ had fusion at an average of 5.5 months. Conclusion: Posteriolateral fusion is still a safe, promising and appealing technique.
\end{abstract}

\section{Keywords}

Spondylolisthesis, Posterolateral Fusion, Functional Outcome

\section{Introduction}

Spondylolisthesis is the subluxation of a vertebral body over another in the sagittal plane and is a relatively frequent mechanism of intervertebral instability spondylolisthesis can be caused by ligamentous laxity, a defect in the pars interarticularis, previous surgery, or may be traumatic and occurs in up to $5 \%$ of the general population

"Corresponding author.

How to cite this paper: Chaitanya, M., Mittal, A., Rallapalli, R., Teja, R. and Prasad, Y.S. (2015) Surgical Management of Spondylolisthesis by Pedicular Screw Rod System and Postero-Lateral Fusion. Open Journal of Orthopedics, 5, 163-174. http://dx.doi.org/10.4236/ojo.2015.56022 
and affects all ages [1] [2]. Vertebra slips out of normal position and the affected vertebra most commonly slip forward causing narrowing of the openings where the nerves pass through, causing pressure on the nerves [3]. The surgical treatment of spondylolisthesis is indicated for cases of neurogenic claudication, intractable radicular pain, severe low back pain, presence of neurological symptoms, and failure of conservative management, radiological instability, progressive worsening of the listhesis, Meyerding grade III and IV listhesis, and spondyloptosis [2] [4]-[6]. The ideal surgical treatment for spondylolisthesis remains controversial [2]. The primary goal of spinal fusion is to remove pain-generating tissues and to alleviate the patients' pain by stabilization of one or more motion segments. The last four decades have witnessed an increased understanding of spinal biomechanics, bone fusion techniques, development of different spinal instrumentation devices, advances in refinement of approaches to the spine, and evolvement of minimally invasive methods; all these have made it possible to stabilize virtually every segment of the spine successfully, regardless of the offending pathology [7]. Hence, the use of spinal instrumentation has increased. The main question in modern spine surgery is "When to fuse" and "How to fuse". Surgical management of degenerative low back pain is perhaps the most controversial issue in spine surgery and the large number of current techniques and approaches speaks to a lack of consensus on the subject [8] [9]. Spinal fusion has been developed as a final course of progressive intents, which are designed to stabilize spine movement, reduce pain, and to moderate further degenerative change [9]-[22]. The goals of surgical treatment for lumbar spinal stenosis include relief of leg and back pain [23] [24]. Although decompression is a standard treatment regimen for the surgical treatment of lumbar spinal stenosis, additional fusion after extensive decompression can be required in many cases. In particular, an extensive facetectomy is needed for decompression of the foraminal stenosis in many cases. Thus, for cases of lumbar foraminal stenosis, a combination of neural decompression and spinal fusion can be performed to achieve the goals of surgical treatment. However, these surgeries are accompanied by substantial complications in patients with multilevel lumbar foraminal stenosis. Lumbar spinal fusion is a common surgical treatment used in disc degeneration, which is related to chronic lower back pain and other spinal disorders, such as disc herniation, spondylolisthesis, facet arthropathy, and spinal stenosis [25] [26]. Since spinal arthrodesis was first reported 90 years ago, various techniques have been developed for lumbar spine fusion [27]. Posterior lumbar fusion has the advantages that these are the purely dorsal approach thus avoiding the risks inherent to an anterior approach. [28], PLF construct reduces the postoperative segmental mobility and permits better graft incorporation [29]. Posterior spinal decompression, stabilization and fusion are associated with acceptable postoperative complication rate when done under fluoroscopic guidance [30]. Outcome is related more to the preoperative neurological deficit and etiology of the indication for surgical stabilization. The availability of intraoperative fluoroscopy and improved access to varieties of spinal titanium implants has revived posterior spinal stabilization techniques with their distinct advantages [8]. Fusion operations in the lumbar spine have become well established over the last two decades. The present study was conducted to review our experience with posterior lumbar fusions for the management of spondylolisthesis and the main aim was to study the efficacy of posterior pedicular screw rod system and posterolateral fusion in terms of functional outcome, to study the complications associated with this treatment modality and to compare the efficacy and complications with the available literature.

\section{Material and Method}

The present is a prospective study conducted in the Department of Orthopedics, Narayana Medical College and General hospital, Chintareddy Palem, Nellore. In present study we evaluated the outcome of surgical management of 86 patients who were operated upon with posterior stabilization using pedicular screw rod system and posterolateral fusion for spondylolisthesis between July 2010 and June 2012 and followed up. The surgical management was done by the same surgeon who is expert in this surgery. This investigation was approved by the local Ethics Committee.

Inclusion criteria

1) Patients age between of 20 - 75 yrs.

2) Both genders.

3) Patients diagnosed with spondylolysis and spondylolisthesis with failed conservative treatment

Exclusion criteria

1) Patients of age less than 20 years and more than 75 years.

2) Patients with Grade-V spondylolisthesis. 
3) Patients who did not have a regular follow up for a minimum period of 6 months.

4) Patients with any other spinal pathologies.

5) Patients who have had earlier surgeries on their spine.

Informed consent was taken from all the patients before giving any kind of treatment.

Conservative management: Patients who were diagnosed with spondylolisthesis irrespective of grade were treated on op basis with bed rest at times of acute exacerbation along with activity modification, weight reduction and analgesics, muscle-relaxants, lumbosacral corset for about 4 - 6 weeks. Non responsive patients were admitted and treated conservatively additionally with pelvic traction and foot end elevations for about another 4 weeks. Additionally physiotherapy in the form of IFT/SWD given. Those patients who have not responded to these conservative lines of management were given counseling for surgery and were taken into consideration. Patient selection: Patients are interviewed and epidemiologic, historical, subjective and physical findings are recorded. Routine plain roentgenograms of the lumbar spine with erect flexion and extension views are obtained and the results recorded. An MRI scan of Lumbo-sacral spine is also done to determine the extent of the nerve root involvement. Based on all available information, a therapeutic and surgical plan is then laid out with a predetermined goal in mind for the surgery. Intra-operative findings confirm or alter the pre operative plan and modifications are made accordingly. As with any major spine surgery, patient selection, education and communications are essential for good clinical and functional results

Operative procedure: After the administration of general anesthetic, the patient is placed on Rolton-Hall frame in prone position on the operating table, with hips in as much neutral as possible and knees in flexion. Proper padding of the pressure points was done. In addition, at least two units of blood are kept on hand. A standard posterior midline incision is made and the paraspinal musculature detached sub periosteally and freed to the outer margins of the transverse processes on either sides. Haemostasis is achieved by means of bipolar electro cauterization and packing. Care is taken to identify and cauterize the dorsal branches of lumbar arteries. Decompression by laminectomy and Facetectomy was done in degenerative type and decompression with foraminotomy and laminotomy was done in isthmic type in required cases. Each nerve root is followed out past its nerve root canal to ensure adequate decompression and remove any other bony or soft tissue impingement. Under c-arm guidance Pedicle screws entry point and insertion as per the following steps: Pre-operative planning using plain radiographs is important in deciding the bone quality, pedicle transverse diameter and screw trajectory

Lordotic curve of the lumbar spine produces a rostral angulation for upper lumbar screws-L5 pedicle screws is 5 to 10 degrees caudally At L1 medial angulation of 5 to 10 degrees is satisfactory. -A wider angle in the coronal plane is necessary to avoid lateral penetration of the pedicle in lower lumbar spine The coronal plane angle increases approximately 5 degrees per level from L1 to the sacrum Under C-arm guidance use awl to penetrate the cortex at entry point and probe to open the canal Confirm pedicle location, orientation and depth using probe.

Pedicle screws insertion: Choose the appropriate screw diameter and length based on pedicle probe feedback. Insert the screwdriver tip into the recess of the pedicle screw and rotate the knob of the retaining sleeve clockwise until the tip of the sleeve is firmly attached to the pedicle screw. Knob should not be grasped during screw insertion as it will cause the retaining sleeve to disengage from the screw. Polyaxial screws head must remain free to adapt its position and is not restricted by, or does not rest on, bony structures. When countersinking, care should be taken in reaming the most superior (and inferior) level to protect the facet joints as it may lead to instability. Use pre-contoured rod or using rod bender contour the rod and insert into screws using rod-pusher. Using ratchet handle clockwise reduce the rod into the screw head until fully reduced. Parallel reduction can be achieved by the simultaneous use of two reduction instruments on the same vertebral body. To ensure optimal cap alignment, insert the locking cap through the rod pusher/counter torque and finally tightened completely to create a fixed point for distraction. Use the distraction forceps to distract the construct if necessary. Counter torque to be done and tightened until there is a tactile release and repeat for all locking caps.

\subsection{Post-Operative Protocol}

The drainage tubes were removed after 48 hours and the patient is allowed to turn in bed. The sutures are removed on 12th day. Patients were allowed to ambulate after drain removal with a lumbosacral belt and the patient is discharged with lumbosacral belt and instructed to continue follow up on a regular basis. After 3 months 
the lumbosacral belt is withdrawn gradually.

\subsection{Outcome Analysis}

Clinical outcome (based on VAS for low back pain, ODI, Radicular pain, Neurological deficits and claudication) and spinal fusion was then assessed by plain lumbar spine radiographs at 2, 4, 8 and 12 months after operation.

\subsection{Statistical Analysis}

The statistical analysis was conducted by means of SPSS-Version-15. Descriptive statistics for Continuous data was presented as mean \pm standard deviation and Categorical data as actual numbers and percentages. Categorical variables were analyzed with Chi Square test. For statistical significance, the probability value of less than 0.05 was considered.

\section{Results}

Total of 86 cases of spondylolisthesis were treated surgically by posterior stabilization using pedicular screw rod system and postero-lateral fusion. Of these cases, 72 cases turned up for follow up till 1 year after surgery while 14 patients were lost to follow up. Of the 86 patients there were 58 females and 28 males. All patients were in the range of 20 years to 75 years with an average age at the time of surgery being 43 years. The patients have duration of symptoms ranging from 1 month to 10 years with a mean time period of 28.6 months. The majority of the patients were housewives followed by those doing heavy manual work. All the 86 patients had low back pain; Radicular pain present in 56 patients; Neurological deficits present in 12 patients; Claudication pain present in 36 patients. No involvement of bowel and bladder in any patient. All patients were requiring NSAID's, bed rest, 45 patients underwent traction and physiotherapy for a variable periods with an average of 6 months. All patients have had paraspinal muscle spasm and spinal tenderness and had reduced spinal movements. Average pre-operative VAS for low back pain was 7.8 and ODI was 52\%. Of total 86 patients, 55 patients had instability at the level of L4-L5 and 31 had L5-S1instability Of total 86 patients, 44 patients had grade 1 slip, 34 patients had grade 2 slip and the rest 8 had grade 3 slip The patients had an average blood loss of about $250 \mathrm{ml}$. In our study there were no instrumentation failure, vascular injury and infection. 8 of the 86 patients, that is $9.3 \%$ developed complications. Intra operatively 8 (9.3\%) patients had dural tear, 2 patient had pedicle failure leading to medial wall penetration and post operatively she developed radicular pain on right side which was of new onset, hence she was revised with removal of instrumentation. Dural tear was tackled by placing free fat graft and water tight closure of all layers. The mean difference between pre operative and post operative VAS and ODI at discharge were $2.6 \mathrm{~cm}(\mathrm{SD}=1.87)$ and $26 \%$ respectively. The mean difference of ODI and VAS was found to be more in males than females. Claudication pain was relieved in all patients. Neurological improvement was seen in 8 out of 12 patients. Sensory improvement was seen in 18 and blunting in 6 patients Post Operative Grade of Slip is shown in (Table 1). Overall outcome had been graded into Good, Fair and Failed depending on VAS, ODI, improvement in radiculopathy and neurological deficits (Table 2 and Table 3). Maximum score-12 and minimum score-4 14 patients did not turn up even for single visit after discharge. So their data was not considered for final analysis. Only 72 patients came for follow up. The average duration of follow up of 13 months ranging from 7 - 23 months The mean difference between pre operative and post operative ODI at 4 months follow up was $28 \%$ and 8 month follow up was found to be $36 \%$. Re-operation rates were $2.7 \%$. Neurological deficits of new onset were $2.7 \%$ compared to $5 \%$ in literatures. Pedicle failure was observed in $2.7 \%$ of patients. 10 patients had Post operatively low back pain, while 6 had radiculopathy and 4 had a limp. Whatever may be the score persistent radiculopathy is considered as failed response. 54 of the 72 patients (75\%) had obtained bony fusion while 18 patients did not. The average time for bony fusion was 5.5 months with the earliest being 4

Table 1. Showing number of patients and reduction in grade of listhesis.

\begin{tabular}{ccc}
\hline Grade & No. of patients \\
\hline Grade 0 & 44 patients \\
Grade I & 28 patients \\
Grade II & 14 patients \\
\hline
\end{tabular}


Table 2. Showing different parameters and their scores.

\begin{tabular}{cccc}
\hline Points & 3 & 2 & 1 \\
\hline VAS difference & $>3.5$ & $>3$ & $<2.94$ \\
ODI difference & $>40 \%$ & $10 \%-40 \%$ & $<10 \%$ \\
Radiculopathy & Absent & Present & Persisting \\
NEUROLOGICAL DEFICITS Improvement & 2 grade & 1 grade & Not improved \\
\hline
\end{tabular}

Table 3. Showing number of patients and outcome score of the study.

\begin{tabular}{ccc}
\hline Outcome & Score & No. of Patients \\
\hline Good & $\geq 10$ & $48(67 \%)$ \\
Fair & $5-10$ & $20(27.5 \%)$ \\
Failed & $\leq 5$ & $4(5.5 \%)$ \\
\hline
\end{tabular}

months and the latest 11 monthsoutcome of study based on age and sex of patients is shown in (Table 4 and Table 5) There was no significant relation between level of instability and final clinical outcome with $\mathrm{p}=0.062$ (outcome of number of patients and grades of slip shown in Table 6. Good outcome was strongly associated with radiological fusion with $\mathrm{p}=0.03$. A case of L4-L5 listhesis with complete work up with pre operative radiograph, MRI, postoperative radiograph and follow up is shown in Figures 1-4.

\section{Discussion}

Adult spondylolisthesis is a radiographically verifiable condition revealed by motion in lumbar segments. It is important to isolate the specific symptoms, signs, and functional disabilities that distinguish spondylolisthesis from other types of low-back pain and sciatica. Despite the conservative treatment previously received by many patients, their symptoms cannot be resolved. In numerous studies, the mean age of the patients being treated for isthmic type spondylolisthesis has ranged from 29.8 to 53.4 years [31] [32]. In a study, the mean age was 47.3 years in patients who underwent PLF procedure [33]. The duration of the symptoms ranged from 8 to 60 months, with a mean duration of 38.4 months. In present study also we had females more than male patients and a mean age was 43 years [31]. The patients have duration of symptoms ranging from 1 month to 10 years with a mean time period of 28.6 months. In accordance with the literature surgery was performed in patients who did not respond to conservative management or who develop neurological deficits at the time of presentation. In our series we had L4-5 level (55 cases) involvement more than L5-S1 level (31 cases) and 44 patients had grade 1 slip, 34 patients had grade 2 slip and the rest 8 had grade 3 slip. Kim et al. reported that $50 \%$ of the defective levels were L4-5, and this ratio was similar to that found in our series (54\%). In a study, the vertebral levels at which the implants were inserted were as follows: L2-3 (one patient), L4-5 (25 patients), and L5-S1 (15 patients) [34]. In one study, the most commonly affected level was L5-S1 followed by L4-5 and L3-L4 respectively [31]. Dantas reported equal number (45\%) of patients involving the L4-L5 and L5-S1 levels [35]. Yan et al. reported the L5-S1 affected rate of 52.27\% and L4-L5 of 47.72\% [1]. Posterolateral fusion has been one of the standards for surgical treatment of lumbar spinal instability, and with the use of spinal instrumentation, it has been widely used for lumbar degenerative pathology [36]. 54 of the 72 patients (75\%) had obtained bony fusion while 18 patients did not [37]. The average time for bony fusion was 5.5 months with the earliest being 4 months and the latest 11 months. Good outcome was significantly associated with younger age group, male gender, lower grade of slip and radiological fusion group. However there was no significant relation between level of instability and final clinical outcome. In spondylolisthesis patients, concern for spinal biomechanics is the key to proper surgical management. Crawford et al. [38] [39] reproduced the lumbar spondylolisthesis grade I using cadaveric specimens and studied the biomechanics of various hardware combinations including cages with and without intersomatic spacers, pedicle screws alone, and pedicle screws with cages. The surgical treatment of choice for the management of spondylolisthesis remains a matter of controversy [2] [40]-[42] and an effective spondylolisthesis surgery involves fusion of the fewest possible segments, minimizes dislocation, achieves adequate decompression, corrects the sagittal axis, and accomplishes fusion. Suk et al. performed decompression, pedicle screw 
Table 4. Showing outcome of study based on age group of patients.

\begin{tabular}{ccccc}
\hline Age Group & Number of patients & Good & Outcome Fair & Failed \\
\hline $21-30$ & 10 & 10 & 0 & 0 \\
$31-40$ & 14 & 8 & 4 & 2 \\
$41-50$ & 28 & 20 & 8 & 0 \\
$51-60$ & 20 & 10 & 8 & 2 \\
\hline
\end{tabular}

Good outcome was significantly associated with younger age group with $\mathrm{p}=0.046$.

Table 5. Showing outcome of the study based on gender.

\begin{tabular}{ccccc}
\hline Sex & No. of Patients & Good & Outcome Fair & Failed \\
\hline Female & 48 & 34 & 10 & 4 \\
Male & 24 & 18 & 6 & 0 \\
\hline
\end{tabular}

Good outcome was associated with male group with $\mathrm{p}=0.038$.

Table 6. Showing outcome of number of patients and grades of slip.

\begin{tabular}{ccccc}
\hline Grade of slip & No of patients & Good & Outcome Fair & Failed \\
\hline Grade I & 42 & 38 & 2 & 2 \\
Grade II & 24 & 10 & 14 & 0 \\
Grade III & 6 & 6 & 4 & 2 \\
\hline
\end{tabular}

Good outcome was strongly associated with lower grade of slip with $\mathrm{p}=0.022$.

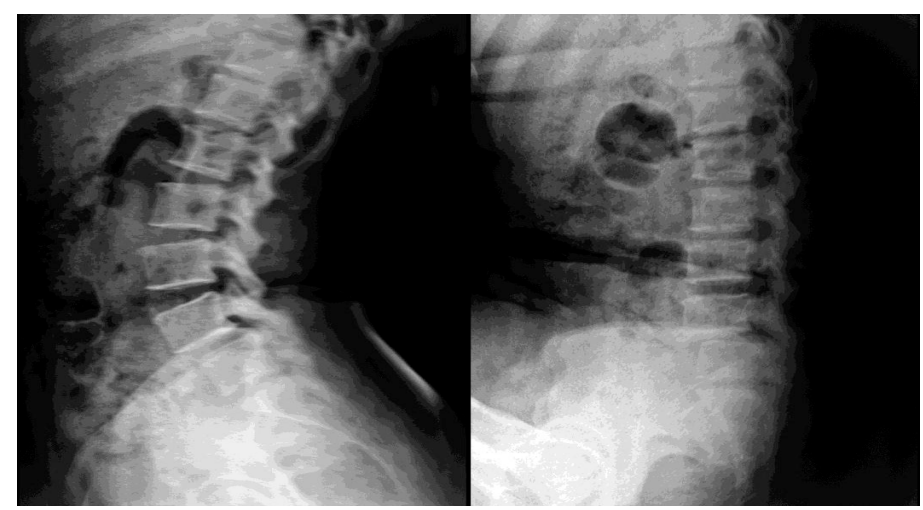

Figure 1. Shows pre of X-ray LS spine (Lateral) showing grade 1 L4-L5 listhesis.

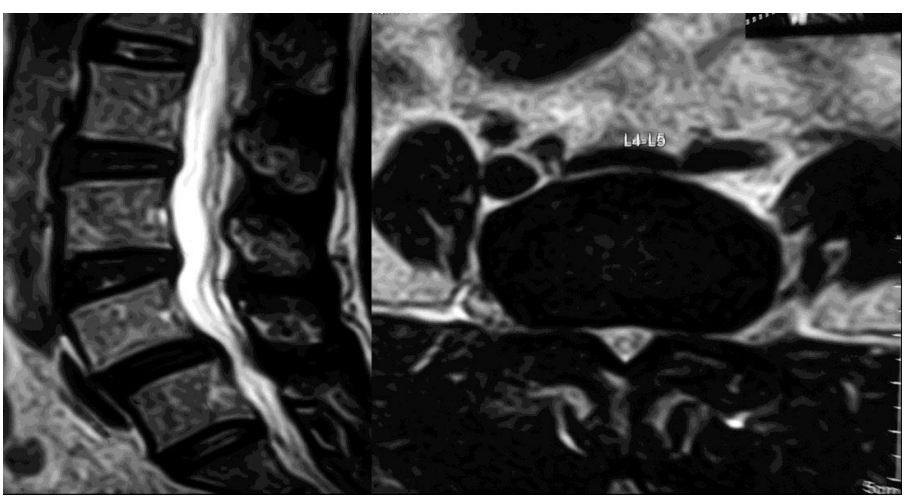

Figure 2. Shows MRI LS spine sagital, axial cut at L4, L5. 


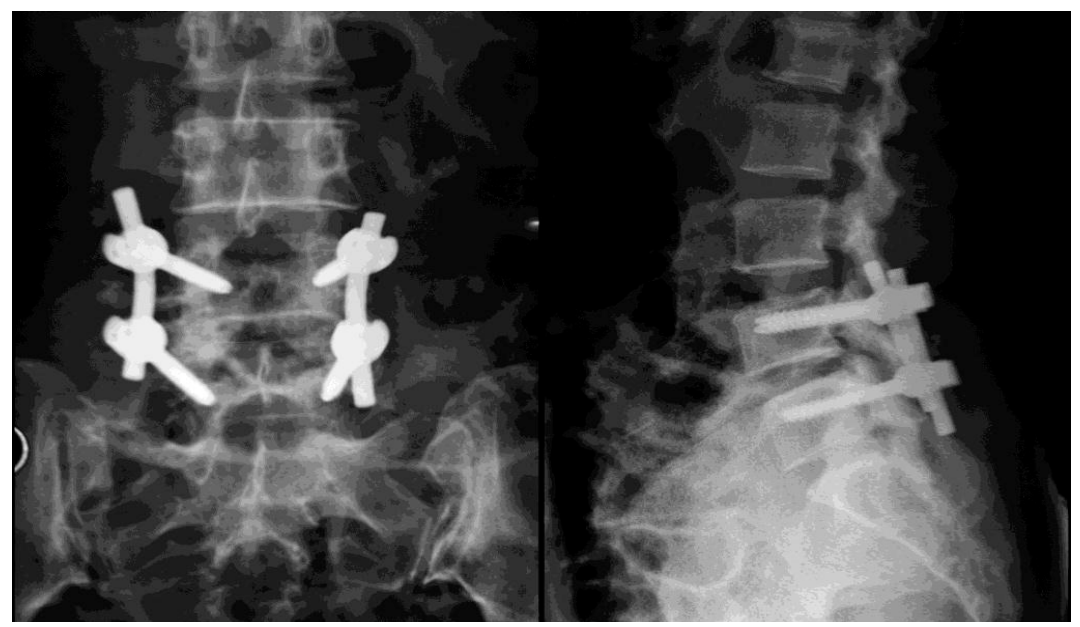

Figure 3. Shows post-op X-ray LS spine A.P., lateral at 3 months with posterior instrumentation.

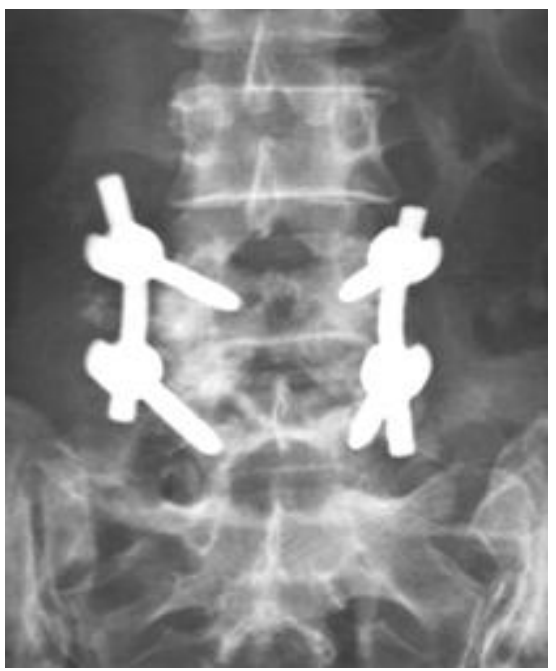

Figure 4. Shows post-op X-ray LS spine AP view at 9 months.

fixation, and fusion in 76 patients with symptomatic spondylolisthesis and a stenotic spinal canal [36] [43]. In the PLF group, the incidence of nonunion was $7.5 \%$, whereas there was no nonunion in the PLIF group. However, in a study it could not be concluded which operative technique (PLF, PLIF, anterior lumbar interbody fusion, or instrumentation) best accomplished fusion [39]. In the management of low-grade isthmic spondylolisthesis, instrumentation, decompression, reduction, and fusion can all play a beneficial role. In a prospective study, however, Kim et al. could not find any differences among clinical outcomes and fusion ratios after observing PLF, PLIF, and combined PLF/PLIF groups for 3 years [42]. In addition, the PLIF-only group showed shorter operating times, lower blood loss, and no pain in the iliac wing (the donor site for bone fusion). All the grade III listhesis were reduced to grade II or I and grade II were reduced to grade I or reduced completely [44]. Grade I listhesis were reduced completely or in situ fixation was performed. In younger patient group the most common type of listhesis seen was dysplastic and in the elder group the degenerative type was the most common. 44 Madan and Boeree compared 23 patients treated with PLIF and 21 treated with PLF who also had instrumentation treatment. Satisfactory clinical outcomes were found at a rate of $69.5 \%$ in the PLIF group and $69.5 \%$ in the PLF group. In patients with low-grade spondylolisthesis, they obtained better clinical results in the PLF group; however, the quality of fusion and correction was better in the PLIF group. After 2 years of experience with PLF and PLIF, Ekman et al. reported that these 2 methods produced similar outcomes in the management of adult isthmic spondylolisthesis (with the exception of higher complication rates when using the PLIF method) 
[45]. Patients with adequate fusion might have a better clinical outcome and vice versa [46]. Some investigators have reported that the clinical outcomes for PLIF are no better than for other fusion techniques [47]. In patients who underwent PLIF, the wider retraction of the nerve root and thecal sac was clearly disadvantageous because it induced leg pain. An Oswestry index of $89 \%$ with good or excellent results in the PLIF patients, and $86 \%$ in PLF patients [48]-[50]. The difference was not statistically significant. In a prospective randomized study on degenerative lumbar disease, three fusion methods: posterolateral fusion (PLF), posterior lumbar interbody fusion (PLIF), and PLIF combined with PLF (PLF + PLIF), were compared and there was no significant differences in clinical results and union rates among the three methods. The reported complications in the PLF patients are screw fractures and loosening of the implants and these may require re-operation [42]. It is generally believed that reduction at operation is not required for patients with symptomatic Grades 1 and 2 spondylolisthesis. Complication rates were reportedly higher in patients who received reduction at operation. Although a sound fusion is thought to be a parameter for clinical success in patients with mechanical LBP, however, the fusion rates did not correlate with the clinical outcomes in patients [51]-[54]. In a prospective study, our aim was to compare the clinical outcome of posterior lumbar interbody fusion (PLIF) and posterolateral fusion (PLF) in spondylolisthesis [55]. Radiography was performed preoperatively and postoperatively to assess the fusion. Both surgical procedures were effective, but the PLF group showed more complications related to hardware biomechanics. The PLIF group presented a better fusion rate than PLF group but there was no significant statistical difference in clinical and functional outcome in the two groups. Swan et al. investigated 2 groups with low-grade isthmic spondylolisthesis; they treated the first group (50 consecutive patients) using 1-level posterior instrumentation and PLF, and they treated the second group (50 consecutive patients) with both anterior lumbar interbody fusion and PLF [56]. At the 2nd year postoperatively, a clinical examination demonstrated that the patients who received the combined anteroposterior treatment showed more correction of their unstable spondylolisthesis than patients who only received posterior treatment. The complications associated with the spine procedure include permanent neurological deficit in $0.4 \%-1.7 \%$, CSF leakage in $0.4 \%-0.5 \%$, radicular pain in $1.1 \%-2.5 \%$, and deep wound infection in $0.6 \%-5 \%$ of patients [57]. The complication rates associated with PLIF are higher than those with PLF and, technically, PLF is easier to perform [58]. In comparison to PLIF, the PLF has less blood loss and PLIF procedure considered to be difficult due to the increased bleeding, prolonged operation time, and more extensive dissection [32] [40] [59]. Cerebrospinal fluid (CSF) leaks can occur as a result of spine surgery or trauma [2]. These leaks represent serious problems because of persistent headaches and the possibility of meningitis. Surgical management is often needed and requires meticulous direct closure of the dura or closure by means of a fascial graft. Based on findings it was concluded that if there is instability affecting the three-column spine in spondylolisthesis, posterior interbody fusion with pedicle screws (PLIF) provides a more solid mechanical construction when compared with the pedicle screws used alone [60]. Both surgical procedures were effective, although the PLF group showed more complications related to hardware biomechanics. Clinical and functional outcomes in both groups were similar, and no significant statistical difference was found. But PLIF presented better fusion rate when compared with PLF. Lumbar spondylolisthesis is a heterogeneous disorder characterised by the forward displacement of one vertebra on another. Conservative treatment for segmental instability is possible for patients with tolerable pain. Surgery is indicated if symptoms are disabling and interfere with work, if the condition is progressive, or if there is a significant neurological deficit. Postero lateral fusion can be a option for the management of Lumbar spondylolisthesis [40]. However this study has limitations as the number of patients included was relatively small and studies with larger numbers of patients are required. With advances in minimal access technology using operating microscope, in future the present techinique can be compared with other approaches providing an adequate decompression and circumferential fusion, and avoid many of the disadvantages of the traditional posterior open approach for degenerative spondylolisthesis.

\section{Conclusion}

Spondylolisthesis is a common condition that is seen in orthopedic practice for low back pain. To treat this many surgical and non-surgical methods have been described in literature. Surgical decompression and spinal stabilization is recommended for those patients who fail to respond to conservative management or who have significant spinal instability. Different techniques i.e. anterior, posterior and or combined approached have been used for various underlying degree of spondylolisthesis. Posterio-lateral lumbar fusion and spinal decompression is an effective method in the treatment of spondylolisthesis, as it provided good spinal fusion, less complication 
with satisfactory clinical outcome. Although the surgical fixation of spondylolisthesis using pedicular screw rod system and posterolateral graft with decompression is a safe, promising and appealing technique especially in low grade listhesis, there is a need to study, adopt and PLIF, TLIF and ALIF procedures to produce better clinical results and in high grade spondylolisthesis. Based on our findings, we conclude that spondylolisthesis is one of the most common indications for posterior spinal decompression, stabilization and postero lateral fusion (PLF) at our center. Surgical procedures were effective with fewer complications related to hardware biomechanics. The surgical procedure was associated with minimal postoperative complications particularly when performed under fluoroscopic guidance. Good outcome was mainly related to the preoperative neurological deficits and the degree of slip. Apart from the surgical management, modification of the lifestyle is also recommended to avoid failure of surgery. Although short-term results from studies are promising, the number of patients included was relatively small and studies with larger numbers of patients are required.

\section{Acknowledgements}

The authors did not receive any funds for the preparation of this manuscript.

\section{Conflict of Interest}

None of the authors has any conflict of interest.

\section{References}

[1] Dantas, F.L.R., Prandini, M.N. and Ferreira, M.A.T. (2007) Comparison between Posterior Lumbar Fusion with Pedicle Screws and Posterior Lumbar Interbody Fusion with Pedicle Screws in Adult Spondylolisthesis. Arquivos de Neuro-Psiquiatria, 65, 764-770. http://dx.doi.org/10.1590/S0004-282X2007000500006

[2] Dai, L.Y., Jia, L.S., Yuan, W., Ni, B. and Zhu, H.B. (2001) Direct Repair of Defect in Lumbar Spondylolysis and Mild Isthmic Spondylolisthesis by Bone Grafting, with or without Facet Joint Fusion. European Spine Journal: Official Publication of the European Spine Society, the European Spinal Deformity Society, and the European Section of the Cervical Spine Research Society, 10, 78-83. http://dx.doi.org/10.1007/s005860000205

[3] Frymoyer, J. and Selby, D. (1985) Segmental Instability. Rationale for Treatment. Spine, 10, 280. http://dx.doi.org/10.1097/00007632-198504000-00017

[4] Roy-Camille, R., Roy-Camille, M. and Demeulenaere, C. (1970) Osteosynthesis of Dorsal, Lumbar, and Lumbosacral Spine with Metallic Plates Screwed into Vertebral Pedicles and Articular Apophyses. La Pressemedicale, 78, 14471448.

[5] Zdeblick, T.A. (1993) A Prospective, Randomized Study of Lumbar Fusion. Preliminary Results. Spine, 18, $983-991$. http://dx.doi.org/10.1097/00007632-199306150-00006

[6] Feffer, H.L., Wiesel, S.W., Cuckler, J.M. and Rothman, R.H. (1985) Degenerative Spondylolisthesis. To Fuse or Not to Fuse. Spine, 10, 287-289. http://dx.doi.org/10.1097/00007632-198504000-00018

[7] Fuji, T., Oda, T., Kato, Y., Fujita, S. and Tanaka, M. (2003) Posterior Lumbar Interbody Fusion Using Titanium Cylindrical Threaded Cages: Is Optimal Interbody Fusion Possible without Other Instrumentation? Journal of Orthopaedicscience: Official Journal of the Japanese Orthopaedic Association, 8, 142-147. http://dx.doi.org/10.1007/s007760300024

[8] Idowu, O.E., Adewole, O.A. and Majekodunmi, A.A. (2012) Posterior Spinal Decompression, Stabilization and Arthrodesis in Nigerian Adults: Profile and Outcome. Nigerian Medical Journal: Journal of the Nigeria Medical Association, 53, 42-46. http://dx.doi.org/10.4103/0300-1652.99832

[9] Janssen, M.E., Lam, C. and Beckham, R. (2001) Outcomes of Allogenic Cages in Anterior and Posterior Lumbar Interbody Fusion. European Spine Journal: Official Publication of the European Spine Society, the European Spinal Deformity Society, and the European Section of the Cervical Spine Research Society, 10, S158-S168.

[10] Agazzi, S., Reverdin, A. and May, D. (1999) Posterior Lumbar Interbody Fusion with Cages: An Independent Review of 71 Cases. Journal of Neurosurgery, 91, 186-192. http://dx.doi.org/10.3171/spi.1999.91.2.0186

[11] Burkus, J.K., Dorchak, J.D. and Sanders, D.L. (2003) Radiographic Assessment of Interbody Fusion Using Recombinant Human Bone Morphogenetic Protein Type 2. Spine, 28, 372-377. http://dx.doi.org/10.1097/01.BRS.0000048469.45035.B9

[12] Chitnavis, B., Barbagallo, G., Selway, R., Dardis, R., Hussain, A. and Gullan, R. (2001) Posterior Lumbar Interbody Fusion for Revision Disc Surgery: Review of 50 Cases in Which Carbon Fiber Cages Were Implanted. Journal of Neurosurgery, 95, 190-195. http://dx.doi.org/10.3171/spi.2001.95.2.0190 
[13] Hashimoto, T., Shigenobu, K., Kanayama, M., et al. (2002) Clinical Results of Single-Level Posterior Lumbar Interbody Fusion using the Brantigan I/F Carbon Cage Filled with a Mixture of Local Morselized Bone and Bioactive Ceramic Granules. Spine, 27, 258-262. http://dx.doi.org/10.1097/00007632-200202010-00011

[14] Janssen, M.E., Nguyen, C., Beckham, R. and Larson, A. (2000) Biological Cages. European Spine Journal, 9, S102S109.

[15] Sasso, R.C., Kitchel, S.H. and Dawson, E.G. (2004) A Prospective, Randomized Controlled Clinical Trial of Anterior Lumbar Interbody Fusion Using a Titanium Cylindrical Threaded Fusion Device. Spine, 29, 113-122; Discussion 121. http://dx.doi.org/10.1097/01.BRS.0000107007.31714.77

[16] Cloward, R.B. (1953) The Treatment of Ruptured Lumbar Intervertebral Discs by Vertebral Body Fusion. I. Indications, Operative Technique, after Care. Journal of Neurosurgery, 10, 154-168. http://dx.doi.org/10.3171/jns.1953.10.2.0154

[17] Brunon, J., Chazal, J. and Chirossel, J.P., et al. (1996) When Is Spinal Fusion Warranted in Degenerative Lumbar Spinal Stenosis? Revue du Rhumatisme (English Edition), 63, 44-50.

[18] Kim, E.-H. and Kim, H.-T. (2009) En Bloc Partial Laminectomy and Posterior Lumbar Interbody Fusion in Foraminal Spinal Stenosis. Asian Spine Journal, 3, 66-72. http://dx.doi.org/10.4184/asj.2009.3.2.66

[19] Postacchini, F. (1999) Surgical Management of Lumbar Spinal Stenosis. Spine, 24, 1043-1047. http://dx.doi.org/10.1097/00007632-199905150-00020

[20] Postacchini, F., Cinotti, G., Perugia, D. and Gumina, S. (1993) The Surgical Treatment of Central Lumbar Stenosis. Multiple Laminotomy Compared with Total Laminectomy. The Journal of Bone and Joint Surgery (British Volume), 75, 386-392.

[21] Sanderson, P.L. and Getty, C.J. (1996) Long-Term Results of Partial Undercutting Facetectomy for Lumbar Lateral Recess Stenosis. Spine, 21, 1352-1356. http://dx.doi.org/10.1097/00007632-199606010-00015

[22] Simmons, E.H. and Capicotto, W.N. (1988) Posterior Transpedicular Zielke Instrumentation of the Lumbar Spine. Clinical Orthopaedics and Related Research, No. 236, 180-191.

[23] Burkus, J.K., Gornet, M.F., Dickman, C.A. and Zdeblick, T.A. (2002) Anterior Lumbar Interbody Fusion Using rhBMP-2 with Tapered Interbody Cages. Journal of Spinal Disorders \& Techniques, 15, 337-349. http://dx.doi.org/10.1097/00024720-200210000-00001

[24] Sasso, R.C., LeHuec, J.C., Shaffrey, C. and The Spine Interbody Research Group (2005) Iliac Crest Bone Graft Donor Site Pain after Anterior Lumbar Interbody Fusion: A Prospective Patient Satisfaction Outcome Assessment. Journal of Spinal Disorders \& Techniques, 18, S77-S81. http://dx.doi.org/10.1097/01.bsd.0000112045.36255.83

[25] Carreon, L.Y., Puno, R.M., Dimar, J.R., Glassman, S.D. and Johnson, J.R. (2003) Perioperative Complications of Posterior Lumbar Decompression and Arthrodesis in Older Adults. The Journal of Bone and Joint Surgery (American Volume), 85-A, 2089-2092.

[26] Cho, K.-J., Suk, S.-I., Park, S.-R., et al. (2008) Short Fusion versus Long Fusion for Degenerative Lumbar Scoliosis. European Spine Journal, 17, 650-656. http://dx.doi.org/10.1007/s00586-008-0615-z

[27] Zhang, Q.H. and Teo, E.C. (2008) Finite Element Application in Implant Research for Treatment of Lumbar Degenerative Disc Disease. Medical Engineering \& Physics, 30, 1246-1256. http://dx.doi.org/10.1016/j.medengphy.2008.07.012

[28] Brantigan, J.W., Steffee, A.D., Lewis, M.L., Quinn, L.M. and Persenaire, J.M. (2000) Lumbar Interbody Fusion Using the Brantigan I/F Cage for Posterior Lumbar Interbody Fusion and the Variable Pedicle Screw Placement System: Two-Year Results from a Food and Drug Administration Investigational Device Exemption Clinical Trial. Spine, 25, 1437-1446. http://dx.doi.org/10.1097/00007632-200006010-00017

[29] Csécsei, G.I., Klekner, A.P., Dobai, J., Lajgut, A. and Sikula, J. (2000) Posterior Interbody Fusion Using Laminectomy Bone and Transpedicular Screw Fixation in the Treatment of Lumbar Spondylolisthesis. Surgical Neurology, 53, 2-6; Discussion 6. http://dx.doi.org/10.1016/S0090-3019(99)00198-6

[30] Panjabi, M.M. (1988) Biomechanical Evaluation of Spinal Fixation Devices: I. A Conceptual Framework. Spine, 13, 1129-1134. http://dx.doi.org/10.1097/00007632-198810000-00013

[31] Ganju, A. (2002) Isthmic Spondylolisthesis. Neurosurgical Focus, 13, 1-6. http://dx.doi.org/10.3171/foc.2002.13.1.2

[32] Fraser, R.D. (1995) Interbody, Posterior, and Combined Lumbar Fusions. Spine, 20, 167S-177S. http://dx.doi.org/10.1097/00007632-199512151-00016

[33] Jacobs, W.C.H., Vreeling, A. and De Kleuver, M. (2006) Fusion for Low-Grade Adult Isthmic Spondylolisthesis: A Systematic Review of the Literature. European Spine Journal, 15, 391-402. http://dx.doi.org/10.1007/s00586-005-1021-4

[34] Kim, J.-S., Lee, K.-Y., Lee, S.-H. and Lee, H.-Y. (2010) Which Lumbar Interbody Fusion Technique Is Better in 
Terms of Level for the Treatment of Unstable Isthmic Spondylolisthesis? Journal of Neurosurgery Spine, 12, 171-177. http://dx.doi.org/10.3171/2009.9.SPINE09272

[35] Stauffer, R.N. and Coventry, M.B. (1972) Posterolateral Lumbar-Spine Fusion. Analysis of Mayo Clinic Series. The Journal of Bone and Joint Surgery (American Volume), 54, 1195-1204.

[36] Yan, D.-L., Pei, F.-X., Li, J. and Soo, C.-L. (2008) Comparative Study of PILF and TLIF Treatment in Adult Degenerative Spondylolisthesis. European Spine Journal, 17, 1311-1316. http://dx.doi.org/10.1007/s00586-008-0739-1

[37] Axelsson, P., Johnsson, R., Strömqvist, B., Arvidsson, M. and Herrlin, K. (1994) Posterolateral Lumbar Fusion. Outcome of 71 Consecutive Operations after 4 (2 - 7) Years. Acta Orthopaedica, 65, 309-314. http://dx.doi.org/10.3109/17453679408995459

[38] Brantigan, J.W. and Neidre, A. (2003) Achievement of Normal Sagittal Plane Alignment Using a Wedged Carbon Fiber Reinforced Polymer Fusion Cage in Treatment of Spondylolisthesis. The Spine Journal, 3, 186-196. http://dx.doi.org/10.1016/S1529-9430(02)00536-3

[39] Suk, S.I., Lee, C.K., Kim, W.J., Lee, J.H., Cho, K.J. and Kim, H.G. (1997) Adding Posterior Lumbar Interbody Fusion to Pedicle Screw Fixation and Posterolateral Fusion after Decompression in Spondylolytic Spondylolisthesis. Spine, 22, 210-219; Discussion 219. http://dx.doi.org/10.1097/00007632-199701150-00016

[40] Inamdar, D.N., Alagappan, M., Shyam, L., Devadoss, S. and Devadoss, A. (2006) Posterior Lumbar Interbody Fusion versus Intertransverse Fusion in the Treatment of Lumbar Spondylolisthesis. Journal of Orthopaedic Surgery (Hong Kong), 14, 21-26.

[41] Kant, A.P., Daum, W.J., Dean, S.M. and Uchida, T. (1995) Evaluation of Lumbar Spine Fusion. Plain Radiographs versus Direct Surgical Exploration and Observation. Spine, 20, 2313-2317. http://dx.doi.org/10.1097/00007632-199511000-00009

[42] Kim, K.I., Kim, S.R., Sasase, N., et al. (2006) 2'-,5'-Oligoadenylate Synthetase Response Ratio Predicting Virological Response to PEG-Interferon-Alpha2b plus Ribavirin Therapy in Patients with Chronic Hepatitis C. Journal of Clinical Pharmacy and Therapeutics, 31, 441-446. http://dx.doi.org/10.1111/j.1365-2710.2006.00761.x

[43] Spruit, M., Pavlov, P.W., Leitao, J., De Kleuver, M., Anderson, P.G. and Den Boer, F. (2002) Posterior Reduction and Anterior Lumbar Interbody Fusion in symptomatic Low-Grade Adult Isthmic Spondylolisthesis: Short-Term Radiological and Functional Outcome. European Spine Journal, 11, 428-433. http://dx.doi.org/10.1007/s00586-002-0400-3

[44] Roche, M.B. and Rowe, G.G. (1951) Anomalous Centers of Ossification for Inferior Articular Processes of the Lumbar Vertebrae. The Anatomical Record, 109, 253-259. http://dx.doi.org/10.1002/ar.1091090208

[45] Madan, S. and Boeree, N.R. (2002) Outcome of Posterior Lumbar Interbody Fusion versus Posterolateral Fusion for Spondylolytic Spondylolisthesis. Spine, 27, 1536-1542. http://dx.doi.org/10.1097/00007632-200207150-00011

[46] Ekman, P., Möller, H., Tullberg, T., Neumann, P. and Hedlund, R. (2007) Posterior Lumbar Interbody Fusion versus Posterolateral Fusion in Adult Isthmic Spondylolisthesis. Spine, 32, 2178-2183. http://dx.doi.org/10.1097/BRS.0b013e31814b1bd8

[47] Ogilvie, J.W. (2005) Complications in Spondylolisthesis Surgery. Spine, 30, S97-101. http://dx.doi.org/10.1097/01.brs.0000155581.81997.80

[48] Hacker, R.J. (1997) Comparison of Interbody Fusion Approaches for Disabling Low Back Pain. Spine, 22, 660-665; Discussion 665. http://dx.doi.org/10.1097/00007632-199703150-00017

[49] Lin, P.M. (1985) Posterior Lumbar Interbody Fusion Technique: Complications and Pitfalls. Clinical Orthopaedics and Related Research, No. 193, 90-102.

[50] Wetzel, F.T. and LaRocca, H. (1991) The Failed Posterior Lumbar Interbody Fusion. Spine, 16, 839-845. http://dx.doi.org/10.1097/00007632-199107000-00027

[51] Dickman, C.A., Fessler, R.G., MacMillan, M. and Haid, R.W. (1992) Transpedicular Screw-Rod Fixation of the Lumbar Spine: Operative Technique and Outcome in 104 Cases. Journal of Neurosurgery, 77, 860-870. http://dx.doi.org/10.3171/jns.1992.77.6.0860

[52] Matthiass, H.H. and Heine, J. (1986) The Surgical Reduction of Spondylolisthesis. Clinical Orthopaedics and Related Research, No. 203, 34-44.

[53] Naderi, S., Manisali, M., Acar, F., Ozaksoy, D., Mertol, T. and Arda, M.N. (2003) Factors Affecting Reduction in Low-Grade Lumbosacral Spondylolisthesis. Journal of Neurosurgery, 99, 151-156. http://dx.doi.org/10.3171/spi.2003.99.2.0151

[54] Poussa, M., Schlenzka, D., Seitsalo, S., Ylikoski, M., Hurri, H. and Osterman, K. (1993) Surgical Treatment of Severe Isthmic Spondylolisthesis in Adolescents. Reduction or Fusion in Situ. Spine, 18, 894-901. http://dx.doi.org/10.1097/00007632-199306000-00014

[55] Turner, J.A., Ersek, M., Herron, L., et al. (1992) Patient Outcomes after Lumbar Spinal Fusions. JAMA, 268, $907-911$. 
http://dx.doi.org/10.1001/jama.1992.03490070089049

[56] Cheng, L., Nie, L. and Zhang, L. (2009) Posterior Lumbar Interbody Fusion versus Posterolateral Fusion in Spondylolisthesis: A Prospective Controlled Study in the Han Nationality. International Orthopaedics, 33, 1043-1047. http://dx.doi.org/10.1007/s00264-008-0588-x

[57] Swan, J., Hurwitz, E., Malek, F., et al. (2006) Surgical Treatment for Unstable Low-Grade Isthmic Spondylolisthesis in Adults: A Prospective Controlled Study of Posterior Instrumented Fusion Compared with Combined Anterior-Posterior Fusion. The Spine Journal, 6, 606-614. http://dx.doi.org/10.1016/j.spinee.2006.02.032

[58] Weatherley, C.R., Prickett, C.F. and O’Brien, J.P. (1986) Discogenic Pain Persisting Despite Solid Posterior Fusion. The Journal of Bone and Joint Surgery (British Volume), 68, 142-143.

[59] Thomsen, K., Christensen, F.B., Eiskjaer, S.P., Hansen, E.S., Fruensgaard, S. and Bünger, C.E. (1997) 1997 Volvo Award Winner in Clinical Studies. The Effect of Pedicle Screw Instrumentation on Functional Outcome and Fusion Rates in Posterolateral Lumbar Spinal Fusion: A Prospective, Randomized Clinical Study. Spine, 22, 2813-2822. http://dx.doi.org/10.1097/00007632-199712150-00004

[60] Chauhan, C., Francis, G.A. and Kemeny, A.A. (1995) The Avoidance of Surgery in the Treatment of Subarachnoid Cutaneous Fistula by the Use of an Epidural Blood Patch: Technical Case Report. Neurosurgery, 36, 612-613; Discussion 613. http://dx.doi.org/10.1227/00006123-199503000-00025 